УДК 821.161.1-32

\title{
Н.И. Погорелова
}

\section{ОСОБЕННОСТИ ХРОНОТОПА «КОЛЫМСКИХ РАССКАЗОВ» В.Т. ШАЛАМОВА}

«Новая проза» В. Шаламова стала отражением трагических катаклизмов XX века. Размышляя о судьбах жертв этого времени, автор находит их художественное выражение в «новом» пространстве и времени. На современном этапе литературоведения значительно возрастает внимание к особым формам организации пространства и времени, присущим «лагерной» прозе - литературе non fiction, с выраженным документальным началом, где собственно сам документализм может проявляться не в точности указываемых дат и имен, а в описании особого эмоционального опыта, порождаемого на этой «территории».

Хронотопическая значимость образа лагеря как территории пребывания и обретения опыта, территории «событий», очевидна для понимания самого понятия хронотопа лагерной прозы как особого жанрового образования. В этом смысле лагерный хронотоп становится значимым для характеристики мира персонажей, для которых присуще особое переживание времени и пространства.

Актуальность исследования хронотопа лагерной прозы В. Шаламова обусловлена потребностью переосмысления опыта человека «в лагерном мире» как предмета художественной литературы. Посттоталитарный синдром свидетельствует о том, что «лагерное» прошлое составляет особый отдельный нарратив, становится частью и национальной памяти, и национального бытия многих народов, и индивидуального переживания, что засвидетельствовано, к примеру, появлением и самого феномена «лагерной прозы», и ряда его исследований в российском и украинском литературоведении. 
142 Наукові записки ХНПУ ім. Г.С. Сковороди. Літературознавство, 2019, вип. 4(94)

Цель статьи заключается в выявлении способов организации хронотопа и описании переживания времени и пространства как территории рождения опыта шаламовского героя.

Особенности хронотопа «Колымских рассказов» выявлены в работах Е. Волковой, Н. Лейдермана, Е. Михайлик, Л. Тимофеева, В. Френкеля, Л. Червяковой. В. Френкель говорит о времени, которого нет, оно статично [7]. Е. Волкова видит «сомкнувшееся до мига» [1] время. Л. Тимофеев называет художественное время исследуемого цикла рассказов временем «небытия» [6]. Е. Михайлик характеризует «шаламовское» время-пространство, наделяя его маркерами «телесности»: «Мерой всех колымских вещей является труп. Мерой колымского пространства - не великое место, занимаемое трупом или заготовкой для трупа» [4, с. 188]. А степень целостности пространства определяется мерой распада описываемой личности под воздействием лагерной вселенной. Е. Михайлик определяет «пространство по Шаламову» как сумму действий, которые люди способны произвести с людьми, и сумму состояний тех людей, с которыми произвели эти действие. Н. Лейдерман назвал мир лагеря «подлинным театром абсурда» [3].

Л. Старикова в статье ««Лагерная проза» в контексте русской литературы XX века: понятие, границы, специфика» дает определение «лагерной прозы» как тематического направления в русском литературном процессе конца $50-\mathrm{x}-90-\mathrm{x}$ гг. XX века, создающее художественный образ лагеря в творческой рефлексии писателей (очевидцев, наблюдателей со стороны, тех, кто не видел вообще или изучал по архивам, воспоминаниям), обладающее следующими чертами: общие тематика и проблематика, связанные с экзистенциальной средой лагеря, автобиографический характер; документальность; историзм; художественное воплощение образа лагеря» [5, с. 169]. Исследование Л. Стариковой важно также для понимания специфики хронотопа лагерной прозы как особого пространства (автор статьи определяет его как «замкнутость, остров, ад»), для которого характерны «особая психология человека, 
философское осмысление человека в ситуации несвободы»; а над всем этим - «особая авторская рефлексия над текстом» [5, с. 169].

Все эти характеристики времени и пространства шаламовской прозы видятся как взаимодополняющие и позволяющие определить наиболее точные хронотопические атрибуты модели мира, характерной для лагерной прозы как специфического жанра со своей содержательной константой.

Исследования пространственно-временных характеристик лагерной прозы В. Шаламова аккумулируют наблюдения над механизмом организации локального изолированного пространства лагеря как особого мира, в котором время обретает собственные законы. Шаламовский опыт описания и переживания лагерного хронотопа видится значительно более сложным, поскольку речь идёт об онтологическом его осмыслении, и интерпретация этого явления составляет новизну предлагаемой статьи.

Понимание времени есть результат общественного культурного договора, а его (времени) границы определены пространством, которое выстраивают люди XX века. Культура человеческих смыслов, детерменированная восприятием ценности индивидуального бытия, в тоталитарной системе приводит героя к выводу, что «Разумного основания у жизни нет - вот что доказывает наше время» («Дождь»; курсив мой. - Н.П.) [8, с. 27]. И время, и пространство, поглощающие человека, становятся атрибутами экзистенциального отчуждения: «Всё было как бы чужое, слишком страшное, чтобы быть реальностью» («Как это началось») [8, с. 369]. Лагерный мир в лагерной прозе образует собственный континуум. И трагедия каждой отдельной судьбы находит свои пути реализации опыта пребывания в этом чужом мире, что порождает экзистенциальное переживание ситуации, создавая хайдеггеровское ощущение «дикта», характерного для процесса «нахождения» писателем «своей ситуации» (термин «Dikt» Хайдеггер вывел в рассуждениях о Георге Тракле). В контексте понимания этого хайдеггеровского концепта В. Шаламов распознает «внутреннее время» своего бытия, не совпадающее с его общеуравнительной 
144 Наукові записки ХНПУ ім. Г.С. Сковороди. Літературознавство, 2019, вип. 4(94)

хронометрией. Автор «Колымских рассказов» нашел свою «ситуацию» и смог овладеть собственным «диктом».

Актуализация пространственно-временных понятий представлена уже самим названием цикла В. Шаламова. Авторефлексию колымского хронотопа находим в его тетради, обозначенной писателем как 1970-I: «Якут или чукча мерит расстояние днями вон до той горы 2 дня. Современный лайнер скорость увеличил в 3000 раз. Расстояние надо мерить не в километрах, а по времени» [9, c. 191-210]. Так автор переносит фокус восприятия пространства, подчёркивая особое значение опыта человека, переживающего время как испытание дистанциями. День - дистанция минимальной памяти героя и максимальной памяти автора. Автор старается обозначить начальную и конечную точки пути, держать в поле зрения «пункт прибытия», наделяя его коннотациями экзистенциальной безысходности: «Трудный день был кончен» («Одиночный замер» $[8$, с. 44]) (курсив мой. - Н.П.). Так в поэтике времени прозы В. Шаламова особое стоическое измерение приобретает метафора смерти (кончины) как выхода из замкнутого пространства - завершенность индивидуального времени человека как начальная точка его выхода за лагерное пространство. Медиатором между лагерным и внелагерным хронотопом является автор, осмысляющий законы жизни и смерти. Это точка смерти, о которой помнят герои в своей обречённости и подсознательном устремлении к свободе пусть даже такой ценой.

Символизм каждодневного умирания / воскрешения дает основу для понимания многомерности хронотопа, где соотносятся малые и большие циклы: дни и годы, рождение и смерть, засыпание/ пробуждение; где исчезают границы между осязаемым и метафизическим («Реальной была минута, час, день от подъема до отбоя - дальше он не загадывал и не находил в себе сил загадывать. Как и все» [8, с. 37]); где событие смерти десакрализируется и демифологизируется в результате обесценивания жизни в тоталитарном пространстве. На стыке понятийных кодов (сакрального и профанного, мифологического и будничного) 
возникает гротесковая аллюзия смерти как явления будничного, а следовательно, такого, которое порождает свой иронический миф или историю, в основе которой на самом деле - глубокая трагедия. Если историческое время предстаёт в его обыденной повторяемости и заданности, то сакральное время (дни, когда онтологическое пространство обозначаемо ритуалами), наполнено вечностью. Проблема сакрального и профанного, их связь с историкокультурным анализом развития современных цивилизаций артикулируются в шаламовском хронотопе лагерного быта и в значительной мере определяют видение модели человека тоталитарной эпохи (того «Другого», опыт которого несоразмерно болеетрагичен)сперспективыпосттоталитарной ипостколониальной критики. В новеллах Шаламова зафиксирован многомерный нравственный опыт как голос «Другого», резонирующий в психологическом лабиринте, который не может покинуть повествователь.

Одна из лагерных новелл - «Шерри-бренди» - посвящается нарочито обыденному восприятию смерти (своеобразного «тупика» в лагерном «лабиринте»), которое становится основой её ироничного дискурса в произведении. Когда умирает один из героев, солагерники стараются скрыть этот факт от лагерного начальства: «...Списали его на два дня позднее, - изобретательным соседям его удавалось при раздаче хлеба двое суток получать хлеб на мертвеца, мертвец поднимал руку, как кукла-марионетка» [8, с. 84]. И, собственно, статус автора-комментатора обеспечивает ироническую коннотацию этого «обыденного» происшествия: «Стало быть, он умер раньше даты своей смерти - немаловажная деталь для будущих его биографов» [8, с. 84]. «Будущие биографы»- символический образ «скрипторов», которым никогда не будет суждено узнать правду, либо зная, не иметь возможности передать её: свидетели-«биографы» так же обречены.

Мёртвая рука, поднятая кем-то живым в бараке, и «рука биографа» будущего заставляют читателя ощутить динамику движения к культурному «небытию». Это неожиданный абсурдный в данном 
146 Наукові записки ХНПУ ім. Г.С. Сковороди. Літературознавство, 2019, вип. 4(94)

пространстве виталистический жест-вызов смерти. А его исключительная визуальность переживается как нечто наделённое ценностными измерениями, ощутимыми и реализуемыми только в обозначенном автором ландшафте. В этом очевиден потенциал метафорического жеста, возможного в таком смысловом наполнении исключительно тут-и-сейчас - то, что немецким эссеистом и новеллистом Го́тфридом Бенном объясняется как важнейшая и значительная в «наше время» формальная проявленность и возможность проявленности: «Проступает новый человеческий силуэт, не религиозное, гуманистическое или аффективное существо, не космический парафраз, но человек как чистая формальная возможность» [2].

Разграничение и понимание времени трагического и времени ироничного - результат понимания персонажного и авторского хронотопов, на стыке которых рождаются особые смыслы, воодушевляющие писателя: «Однообразие, повторение - вот обязательная почва науки. То, что в смерти неповторимо, искали не врачи, а поэты» («Шерри-бренди») [8, с. 90].

В статье «О прозе» В. Шаламов обращается к аудитории с размышлениями о лагерном опыте как о трагическом и однозначно негативном: «Автор «Колымских рассказов» считает лагерь отрицательным опытом для человека - с первого до последнего часа. Человек не должен знать, не должен даже слышать о нём. Ни один человек не становится ни лучше, ни сильнее после лагеря. Лагерь отрицательный опыт, отрицательная школа, растление для всех - для начальников и заключённых, конвоиров и зрителей, прохожих и читателей беллетристики» [8, с. 16].

В новелле «Красный крест» В. Шаламова авторская сентенция о деструктивности лагерного пространства по отношению к личности достигает особой обобщённости (никто и ничто не может вырваться из лагерного круга) и усиливается повторяемостью запретительных «ни»/«не»: «Лагерь - отрицательная школа жизни ичеликом и полностью. Ничего полезного, нужного никто оттуда не вынесет, ни сам заключённый, ни его начальник, ни его охрана, ни невольные 
свидетели - инженеры, геологи, врачи, - ни начальники, ни подчинённые» (курсив мой. - Н.П.) [8, с. 184].

Философия лагерного времени у Шаламова позволяет рассматривать лагерное пространство как нечто между жизнью и смертью, откуда, однако, невозможен «разворот» к жизни. Лагерь не только убивает человека, но и прозаичностью статуса смерти омертвляет его душу. Шаламовское ощущение времени и пространства определено самим автором «Колымских рассказов» трагически точно: «Я возвращался из ада» [8, с. 657].

Хронотопическую выраженность приобретают запретительные жесты и предписания лагерного начальства: они не только ограничивают личное пространство заключённых, но и разрушают его, лишая права на выбор под страхом наказания. «Mbl не могли выходить из шурфов - мы были бы застрелены. Ходить между шурфами мог только наш бригадир. Mbl не могли кричать друг другу - мы были бы застрелены. И мы стояли молча, по пояс в земле, в каменным ямах, длинной вереницей шурфов, растягиваясь по берегу высохшего ручья» (курсив мой. - Н.П.) [8, с. 52].

Соотношение хронотопов эпохи тоталитаризма и индивидуальноличностного времени-пространства человека в мире тоталитаризма дает ключ к пониманию писателем смысла человеческого прогресса и «геометрического» символизма «пирамиды» власти. Разрушить её может лишь идеологическая эрозия и непрочность фундамента, состоящего из миллионов «сакральных» жертв. И если революционная жертва могла бы ещё быть оправдана как «строительная», то количество последующих жертв опрокидывало эту пирамиду: слишком тяжёлой является греховная ноша, демифологизирующая и героический статус «строителя» «светлого будущего» (универсальной утопической мифологемы как основы одного из советских сюжетов). Собственно так новые координаты приобретают территории свободы и несвободы: последняя поглощает и тех, кто изначально мыслит себя ограничителями свободы. И, напротив, более свободными показаны в «Колымских рассказах» жертвы системы запретов. Свобода как неограниченное пространство 
148 Наукові записки ХНПУ ім. Г.С. Сковороди. Літературознавство, 2019, вип. 4(94)

восполняется их переживаниями контакта с миром-большим-чемлагерь (воспоминания, ощущение непрерывности природного цикла и неизменности законов природы, её наивысшей правды и права жить).

Шаламовым трагически осмысливается деструктивное начало системы запретов. Но не менее разрушительным фактором в шаламовском дискурсе тоталитаризма предстаёт система неограниченного своевластия и номенклатурной вседозволенности, разрушающих человека; ощущения человека на грани физиологического, животного существования: «Человек живёт не потому, что во что-то верит, на что-то надеется, инстинкт жизни хранит его, как хранит любое животное, любое дерево, камень, собаку» («Сентенция») [8, с. 159].

Замкнутый мир героев в чужом пространстве оказывается для автора своим и свободным в нравственно-оценочных суждениях. Анализируя «пограничные» состояния и логику колымского пространства с его экзистенционными «порталами», Шаламов приходит к определению меры распада описываемой личности на этой территории нечеловеческих трагедий под тяжестью сизифовой обречённости испытания новым днём. «Ограниченность пространства - тюремная камера, арестантский вагон, барачная теснота - продиктовало приемы захвата, укуса, перелома. Но сейчас сил нет и для этого. Я могу только рычать, материться. Я сражаюсь за каждый день, за каждый час отдыха. Каждый клочок тела подсказывает мне мое поведение» («Тайга золотая») [8, с. 136]. Арестантский вагон - это то, что движется согласно заданной кем-то всемогущим траектории, соединяя в пространстве две территории несвободы.

Время автора в «Колымских рассказах», как и время героя, реализует опыт выжившего, но не забывшего лагерный опыт, который даёт возможность говорить о переоценке истин, о том, что «внутреннее время» своего бытия («Я-время») создает не полностью унифицированную реальность. В «Колымских рассказах» день - это больше, чем история нескольких жизней. Замкнутый мир героев в 
чужом пространстве для автора оказывается своим и свободным. «Наше время»- это не только периодичность внутренних и внешних событий, но и неповторимость и энергия в пространстве художественного «я».

Временные последовательности в текстах В. Шаламова расположены друг над другом, подчиняясь законам мироздания и универсальному закону цикличности природы - мира, расположенного вовне, за периметром колючей проволоки, которая удерживает человека. Этот периметр отделяет две модели бытия, отличающиеся собственными законами: если территория лагеря отягощает человека ощущением безысходной повторяемости каждодневного подвига выживания и ожиданием смерти как избавления, то территория вовне - это время ежегодного весеннего витализма, и весенние знаки могут лишь осторожно прокрадываться на территорию лагеря, также преодолевая колючую проволоку. Тот, кто находится на территории лагеря, не мыслит категориями зимы и весны (холода и тепла), ему доступна лишь осязаемость дня и ночи, («свёрнутый», сжатый цикл). И первая, и вторая модели соотносятся по принципу объективной экзистенции.

Лагерное пространство и внеположное пространство «мира»в персонажном дискурсе реконструируются в единый ландшафт во внутреннем пространстве героя: шаламовский герой «носит» в себе «лагерное» пространство не как единственно возможное и реальное его реальность наполнена памятью о том, что было до начала тюремно-лагерного настоящего. «Я знаю, что у каждого человека здесь было свое самое последнее, самое важное - то, что помогало жить, цепляться за жизнь, которую так настойчиво и упорно у нас отнимали. Если у Замятина этим последним была литургия Иоанна Златоуста, то моим спасительным последним были стихи - чужие любимые стихи, которые удивительным образом помнились там, где все остальное было давно забыто, выброшено, изгнано из памяти» $[8,152]$ «Внутреннее время» - это не только субъективное ощущение временной последовательности, но и субъективная культурная составляющая опыта («клочок тела», «чужие любимые стихи», 
150 Наукові записки ХНПУ ім. Г.С. Сковороди. Літературознавство, 2019, вип. 4(94)

переживание их чтения кем-то). Культура становится спасительной живительной субстанцией, которая вливается в лагерное пространство, минуя лагерные ограждения, поскольку мир культуры капсулирован памятью «лагерного» человека, и его нельзя изъять.

Соотношение личного хронотопа героя Шаламовских рассказов, хронотопа автора и собственно пространственно-временных характеристик лагерного быта и бытия требуют изучения в контексте тоталитарного опыта «лагерного поколения» и постоталитарного сознания.

В «Колымских рассказах» перспектива - временная, пространственная - состоит из дней и метров, измеряется биографиями героев и ограничивается завершёнными сюжетами. В обыденной жизни лагеря они символизируют хронотоп несвободы. Реалистические и символические «детали-символы», «детализнаки» получают философски-символическое значение как маркеры времени и пространства. Лагерный мир в лагерной прозе - это не только засвидетельствованное время чужой, закрытой эпохи, но и ощущение границ конкретных духовных, внутренних, свободных, своих автобиографий. Это миромоделирование, обусловленное экзистенциональным переживанием абсурда самой ситуации несвободы и насилия над личностью.

Шаламовское анатомирование пространства реализовано через дискурс телесности (бараки как «анатомический театр» со своей внутренней моделью мира) и его особое переживание «географии» (Колыма как уже не-экзотический сюжет в стране, где лагерниками стали миллионы). Хронотопы героев - это схема пути человекажертвы, ищущего выход из абсурдного мира тотальной несвободы, когда внутренней тюрьмой для узника становятся понимание вседозволенности власти, страх и чувство безысходности.

Перспективы исследования. Лагерная проза В. Шаламова, как и других русских писателей (Е. Гинзбург, А. Солженицын), может стать предметом компаративных исследований, которые значительно расширят горизонты понимания антитоталитарного дискурса в литературе. Дальнейший анализ может быть продуктивным в 
контекстуальном поле лагерной новеллистики Б. АнтоненкаДавыдовича («Сибирские новеллы»), опыта описания лагерного мироустройства У. Самчуком («Ост») и тюремно-лагерных испытаний (территории экзистенционального противостояния человека и системы), описанных И. Багряным («Сад Гефсиманский», «Тигроловы»).

\section{Литература}

1. Волкова Е. Варлам Шаламов: поединок слова с абсурдом. Вопросы литературы. 1997. № 6. С. 3-35.

2. Гуго Ф. Структура современной лирики: от Бодлера до середины двадцатого столетия: Пер. с нем. и комент. Е.В.Головина. Москва: Языки славянских культур, 2010. 344 с.

3. Лейдерман Н. «В метельный, леденящий век»: о «Колымских рассказах» В. Шаламова». Русская литературная классика XX века: Монографические очерки. Екатеринбург: Урал. гос. пед. ун-т, 1996. $308 \mathrm{c.}$

4. Михайлик Е. Незаконная комета. Варлам Шаламов: опыт медленного чтения. Москва: «Новое литературное обозрение», 2018. 376 с.

5. Старикова Л. «Лагерная проза» в контексте русской литературы: понятие, границы, специфика. Вестник Кемеровского государственного университета. 2015. № 2-4 (62). Т. 4. С. 169-174.

6. Тимофеев Л. Поэтика лагерной прозы. Первое чтение «Колымских рассказов» В. Шаламова. Октябрь. 1991. № 3. С. 182-195.

7. Френкель В. В круге последнем: В. Шаламов и А. Солженицын. Даугава. 1990. № 4. С. 79-82.

8. Шаламов В. Сочинения: В 2 т. Т. 1. Колымские рассказы. Екатеринбург: «У-Фактория», 2004. 704 с.

9. Шаламовский сборник. Вып. 5. Вологда; Новосибирск: Common place, 2017. $626 \mathrm{c}$.

\section{References}

1. Volkova Ye. Varlam Shalamov: poedinok slova $\mathrm{s}$ absurdum [Varlam Shalamov: duel words with absurdity]. Voprosy literatury. 1997. № 6. S. 3-35.

2. Gugo F. Struktura sovremennoy liriki: ot Bodlera do serediny dvadtsatogo stoletiya [The structure of modern lyrics: from Baudelaire to the mid- 
152 Наукові записки ХНПУ ім. Г.С. Сковороди. Літературознавство, 2019, вип. 4(94)

twentieth century]: Per. s nem. i koment. Ye.V.Golovina. Moskva: Yazyki slavyanskikh kultur, 2010. $344 \mathrm{~s}$.

3. Leyderman N. «V metelnyy, ledenyashchiy vek»: o «Kolymskikh rasskazakh» V. Shalamova». Russkaya literaturnaya klassika XX veka [“In a blizzard, chilling age": about V. Shalamov's "Kolyma stories". Russian literary classics of the 20th century]: Monograficheskie ocherki. Yekaterinburg: Ural. gos. ped. un-t, 1996. 308 s.

4. Mikhaylik Ye. Nezakonnaya kometa. Varlam Shalamov: opyt medlennogo chteniya [Illegal comet. Varlam Shalamov: the experience of slow reading]. Moskva: «Novoe literaturnoe obozrenie», 2018. 376 s.

5. Starikova L. «Lagernaya proza» v kontekste russkoy literatury: ponyatie, granitsy, spetsifika ["Camp prose" in the context of Russian literature: concept, boundaries, specificity]. Vestnik Kemerovskogo gosudarstvennogo universiteta. 2015. № 2-4 (62). T. 4. S. 169-174.

6. Timofeev L. Poetika lagernoy prozy. Pervoe chtenie «Kolymskikh rasskazov» V. Shalamova [Poetics of camp prose. The first reading of "Kolyma stories" by V. Shalamov]. Oktyabr. 1991. № 3. S. 182-195.

7. Frenkel V. V kruge poslednem: V. Shalamov i A. Solzhenitsyn [In the last circle: V. Shalamov and A. Solzhenitsyn]. Daugava. 1990. № 4. S. 79-82.

8. Shalamov V. Sochineniya: V 2 t. T. 1. Kolymskie rasskazy [Kolyma stories]. Yekaterinburg: «U-Faktoriya», 2004. 704 s.

9. Shalamovskiy sbornik [Shalamovsky collection]. Vyp. 5. Vologda; Novosibirsk: Common place, 2017. 626 s.

\section{Анотація}

\section{Н.І. Погорелова. Особливості хронотопу «Колимських оповідань»}

\section{В.Т. Шаламова}

Одним із значних і яскравих явищ «табірної прози» в російській літературі $\epsilon$ цикл «Колимських оповідань» В. Шаламова, унікальний своїм екзистенційним дискурсом і філософією протистояння людини й системи, особливим переживанням катастрофізму таборового побуту й трагізму несвободи людини. Морально-філософський, онтологічний потенціал «Колимських оповідань» зафіксований в хронотопічних особливостях циклу В. Шаламова як інваріанті «літератури пам'яті», наділеному особливими жанровими атрибутами - у «табірній прозі».

У статті поданий аналіз «Колимських оповідань» як шаламівського досвіду світомоделювання табору - території, на якій час диктує власні 
закони й проявляє свою трагічну незворотність. Хронотопічні особливості буття людини, яка перебуває в таборовому світі, особливості сприймання й зображення просторово-часових характеристик цього світу, деформації й зміщення його координат, подолання дискретності й роль пам'яті як форми існування часу особистого - ті важливі особливості поетики хронотопу, які складають предмет дослідження.

У поетиці часу прози В. Шаламова особливого виміру набуває метафора смерті як способу виходу з ізольованого простору. Циклізація часу постає через метафору щоденного помирання / воскресіння (засинання i пробудження) мешканців таборових бараків. Усвідомлення багатомірності хронотопу «Колимських оповідань» відбувається через співвідношення малих і великих циклів, коли зникають межі між тим, що можна осягнути, й метафізичним, коли смерть стає головною подією в табірній хроніці. Але при тому сама смерть десакралізується й деміфологізується в результаті знецінювання життя в обмеженому ворожому просторі.

На помежів'ї понятійних кодів сприйняття світу - сакрального і профанного, міфологічного й буденного - виникає екзистенційна парадигма хронотопу шаламівського циклу табірної прози.

Ключові слова: табірна проза, хронотоп (часопростір), екзистенційний простір, антітоталітарний дискурс.

\section{Аннотация \\ Н.И. Погорелова. Особенности хронотопа «Колымских рассказов» В.Т. Шаламова}

Одним из значительных и ярких явлений «лагерной прозы» в русской литературе является цикл «Колымских рассказов» В. Шаламова, уникальный своим экзистенциональным дискурсом и философией противостояния человека и системы, особым переживанием катастрофизма лагерного бытия и трагизма несвободы человека. Нравственнофилософский, онтологический потенциал «Колымских рассказов» зафиксирован в хронотопических особенностях цикла В. Шаламова как инварианте «литературы памяти», наделённом особыми жанровыми атрибутами - «лагерной прозе».

В статье представлен анализ «Колымских рассказов» как шаламовского опыта мироописания лагеря - территории, на которой время диктует собственные законы и проявляет трагическую необратимость. Хронотопические особенности бытия человека, пребывающего в лагерном 
154 Наукові записки ХНПУ ім. Г.С. Сковороди. Літературознавство, 2019, вип. 4(94)

мире, особенности восприятия и описания пространственно-временных характеристик этого мира, деформации и смещения его координат, преодоление дискретности и роль памяти как формы существования времени личного - те важные особенности поэтики хронотопа, которые составляют предмет исследования.

В поэтике времени прозы В. Шаламова особое измерение приобретает метафора смерти как способа ухода из изолированного пространства. Циклизация времени представлена метафорой каждодневного умирания / воскрешения (засыпания и пробуждения) обитателей лагерных бараков. Понимание многомерности хронотопа «Колымских рассказов» происходит через соотношение малых и больших циклов, когда исчезают границы между осязаемым и метафизическим, когда смерть становится главным событием лагерной хроники. Но при этом сама смерть десакрализируется и демифологизируется в результате обесценивания жизни в ограниченном враждебном пространстве.

На стыке понятийных кодов восприятия мира - сакрального и профанного, мифологическогоибудничного-возникаетэкзистенциональная парадигма хронотопа шаламовского цикла лагерной прозы.

Ключевые слова: лагерная проза, хронотоп, экзистенциональное пространство, антитоталитарный дискурс.

\section{Summary}

\section{N.I. Pogorelova. Chronotop features of "Kolimskiye novels"}

\section{by V.T. Shalamov}

A series of "Kolimskiye Novels" by V. Shalamov is one of the most significant and bright phenomenon of "camp prose" in Russian literature. It's unique due to its existential discourse and philosophy of confrontation between a person and the system, experience of catastrophe of living in a camp, and tragedy of no freedom. Moral, philosophic, and ontological potential of "Kolimskiye Novels" is fixed in chronological (chronotop) characteristics of the series by Shalamov, so called "memory literature", which has got special genre attributes - "camp prose".

The analysis of "Kolimskiye Novels" as Shalamov's experience of a camp description is represented in the article. Camp is the territory where time dictates its own rules and has some tragic irreversibility. The chronological features of the existence of a person who lives in this special camp world, the peculiarities of the perception and description of space- and time characteristics of this world, 
deformation and displacement of its coordinates, overcoming of discreteness, and the role of memory as a form of existence of so called personal time are those crucial features of chronological poetics which have being investigated.

In the prose poetics by Shalamov, the metaphor of death as the way of escaping the isolated space, becomes very significant. Cyclization of time is represented by the metaphor of daily death and resurrection (sleeping and awakening) of the camp dwellers. It is possible to understand the chronological multidimensionality in "Kolimskiye Novels" with the help of balance between big and small cycles, when the border between something tangible and metaphysical disappears, and death becomes the main event in the camp chronics. And yet, death itself stops being sacral and mythological due to depreciation of life in the limited hostile environment.

At the interface of the conceptual code of the world perception (sacral and profane, day-to-day and mythological) appears an existential paradigm of chronologic of the series of camp prose by Shalamov.

Key words: camp prose, chronotop, existential space, anti-totalitarian discourse.

\section{Інформація про автора}

Погорєлова Наталія Іванівна - аспірантка кафедри світової літератури Харківського національного педагогічного університету імені Г.С. Сковороди; вул. Валентинівська, 2, м. Харків, Україна, 61168; e-mail: maslova2019n@gmail.com; http://orcid.org/0000-0003-2928-8311. 